\title{
SPATIAL AND TEMPORAL CHARACTERISTICS OF PAN EVAPORATION IN THE HUAIHE RIVER BASIN DURING 1951-2015
}

\author{
YANG, M.-Z. ${ }^{1}-$ ZHONG, P. A. ${ }^{1,2^{*}}-$ LI, J.-Y. ${ }^{1}-$ CHEN, J. ${ }^{1}-$ WANG, W.-Z. ${ }^{1}-$ ZHU, F.-L. ${ }^{1}-$ \\ WU, Y.-N. ${ }^{1}-\mathrm{XU}$, B. $^{1}-\mathrm{YAN}, \mathrm{K}^{3}-\mathrm{LIU}, \mathrm{W} .-\mathrm{F} .{ }^{1}-\mathrm{LI}, \mathrm{Y} .-\mathrm{H} .{ }^{1}$ \\ ${ }^{1}$ College of Hydrology and Water Resources, Hohai University \\ No.1, Xikang Road, Nanjing 210098, China \\ ${ }^{2}$ National Engineering Research Center of Water Resources Efficient Utilization and \\ Engineering Safety, Hohai University, No.1, Xikang Road, Nanjing 210098, China \\ ${ }^{3}$ Zhejiang Institute of Hydraulics \& Estuary \\ No.50, Fengqi East Road, Hangzhou 310020, China \\ *Corresponding author \\ e-mail:zpa_hhu@163.com
}

(Received 20 ${ }^{\text {th }}$ Jul 2018; accepted $5^{\text {th }}$ Nov 2018)

\begin{abstract}
The Huaihe River Basin (HRB) in China is located in the middle latitude zone with a land-tosea transitional characteristic, which is sensitive to climate change. Based on the daily pan evaporation $\left(\mathrm{E}_{\mathrm{pan}}\right)$ data from 26 meteorological stations, we investigated the temporal and spatial characteristics of $\mathrm{E}_{\mathrm{pan}}$ across the HRB from 1951 to 2015. Our results indicate that the annual average $\mathrm{E}_{\mathrm{pan}}$ showed a single peak characteristic and mainly peaked in spring and summer, gradually increased from southeast to northwest, coastal area to inland, and humid area to semi-humid area. The annual average $\mathrm{E}_{\mathrm{pan}}$ changed significantly both in 1966 and 1985, dividing the series into three periods, including: significant increasing period, significant declining period and slight increasing period. The $\mathrm{E}_{\mathrm{pan}}$ of the majority of stations exhibited three obvious changing periods, of which the first two periods were consistent with the basin average, and the third one can be categorized into two types, i.e., the descending-to-ascending period and the steep decreasing period. The air temperature $\left(T_{a}\right)$ and $E_{p a n}$ showed periodically contradictions. Specifically, they both presented increasing trends during 1951-1966 and 1986-2015, while during 1967-1985, there existed pan evaporation paradox. Therefore, $\mathrm{T}_{\mathrm{a}}$ is not the dominant factor of $\mathrm{E}_{\mathrm{pan}}$.
\end{abstract}

Keywords: climate change, evaporation paradox, variation, E601 pans, D20 pans, distribution

\section{Introduction}

Evaporation is an indispensable variable in both of the surface heat balance equation and water balance equation. In fact, compared with the reference evapotranspiration and free water evaporation, the actual evapotranspiration is a direct participant in the process of water balance and has long been a major concern. However, it is difficult to measure actual evapotranspiration accurately by different kinds of instruments because the physical mechanism of actual evapotranspiration is too complex. In contrast, $\mathrm{E}_{\mathrm{pan}}$ has a long history of observation and its data series can be easily obtained. As a result, people often calculate the actual evapotranspiration indirectly by $\mathrm{E}_{\mathrm{pan}}$, considering the close relationship between them (Brutsaert and Parlange, 1988; Lawrimore and Peterson, 2000; Golubev et al., 2001; Xu et al., 2006; Zuo et al., 2016). It will be of great significance to study the variation of $E_{p a n}$ since it can assist in sharpening our understanding about climate change and the mechanism of water cycle. 
In the recent century, $\mathrm{T}_{\mathrm{a}}$ has risen remarkably (Rudd and Kay, 2016; Yang et al., 2017). It is widely acknowledged that global warming would make the atmosphere drier and accelerate evaporation from terrestrial open water bodies. However, Peterson et al. (1995) found that $\mathrm{E}_{\mathrm{pan}}$ over most regions of the United States and the former Soviet Union has declined significantly since the 1950s. Therefore, the finding gave rise to a popular research topic called "pan evaporation paradox" or "evaporation paradox" (Roderick and Farquhar, 2002). Hydrologists and meteorologists around the world have already proved the existence of the evaporation paradox. Roderick and Farquhar (2004) found that the $\mathrm{E}_{\mathrm{pan}}$ in Australia (Oceania) decreased at a rate of $-4 \mathrm{~mm} / \mathrm{a}$ from 1970 to 2002. Hoffman et al. (2011) found that in southern Africa (Africa), the $E_{p a n}$ had a -9.1 $\mathrm{mm} / \mathrm{a}$ declining trend during the period from 1974 to 2005. Liu et al. (2004) divided China (East Asia) into eight climate zones and they discovered that from 1955 to 2000, the $\mathrm{E}_{\mathrm{pan}}$ significantly decreased except for the northeast region. They also hold the view that the decreasing rate reached the highest in northwest and the lowest in southwest. In addition, UK (Europe) (Stanhill and Möller, 2008), Thailand (Southeast Asia) (Tebakari et al., 2005), India (South Asia subcontinent) (Chattopadhyay and Hulme, 1997; Jaswal et al., 2008; Jhajharia et al., 2009, 2012; Padmakumari et al., 2013) and other countries and regions have also been confirmed of having significant $\mathrm{E}_{\mathrm{pan}}$ downward trends. During 1990-2000, in order to reveal the actual causes of $E_{p a n}$ decreasing and their impact on climate change and water resources, a group of scientists carried out a large amount of attribution recognition work (Morton, 1983; Stanhill and Cohen, 2001; Cohen et al., 2002; Xu et al., 2005; Rayner, 2007; Roderick et al., 2007; Zheng et al., 2009; Güldal and Tongal, 2008) as well as continuously confirming the significant decreasing trend of $\mathrm{E}_{\text {pan }}$ (Hobbins et al., 2001; Roderick and Farquhar, 2005; Yang et al., 2006, 2007; Li et al., 2013a; He et al., 2017).

At the beginning of this century, however, there has been a challenge to evaporation paradox in China. Cong et al. $(2008,2009)$ first discovered that $E_{p a n}$ has stopped decreasing and reversely turned upward. According to the daily $\mathrm{E}_{\mathrm{pan}}$ observation data from 353 meteorological stations across China during 1956-2005, they found that the whole country's $E_{\text {pan }}$ (except for the south area) showed an upward trend from the middle of the 1980s and the evaporation paradox would no longer exist. Li et al. (2013b) believed that the continued declining trend of $\mathrm{E}_{\mathrm{pan}}$ in arid areas of China stopped around 1993 and then increased at a rate of $10.7 \mathrm{~mm} / \mathrm{a}$. Liu et al. (2011) hold a point of view that the increasing rate of $E_{p a n}$ in China was $7.9 \mathrm{~mm} / \mathrm{a}$ during 1992-2007.

There were a number of published papers concerning the change of $E_{p a n}$ and its attribution in the HRB from the end of twentieth century to the beginning of this century. Rong et al. (2011) found that $\mathrm{E}_{\text {pan }}$ in the basin showed a significant decreasing trend during 1960-2007 and it decreased rapidly in the northern and western parts. The decrease of $\mathrm{E}_{\mathrm{pan}}$ was reported to be caused by the decrease of wind speed and sunshine duration along with the increase of relative humidity and precipitation. Guo and Ren (2005) believed that $\mathrm{E}_{\mathrm{pan}}$ of the basin presented a downward trend from 1960s to 1990s. They speculated that the direct cause of $\mathrm{E}_{\mathrm{pan}}$ decrease was the reduction of solar radiation. The decline of wind speed and diurnal temperature range may also play important roles. Ren and Guo (2006) found that the decreasing rate of $E_{p a n}$ in the basin was $-54.6 \mathrm{~mm} / 10$ a from 1956 to 2000, which was the largest among those around the country. Besides, the $\mathrm{E}_{\mathrm{pan}}$ mainly decreased during 1956-1979, especially in summer, 
and the main attributing factors were wind speed, air temperature as well as sunshine duration.

Little attention has been paid to the $\mathrm{E}_{\mathrm{pan}}$ of the HRB during the recent decade, especially to the analysis about whether the downward trend has stopped or presenting a reverse trend, while no related reports have been published yet. In view of this, we choose the HRB as the study area to conduct an analysis concerning the variation of $\mathrm{E}_{\mathrm{pan}}$. On the basis of previous results, we extend the data series for 10 to 20 more years so as to ensure that this study referred to the latest data series.

The paper is organized with two main objectives. The primary goal is to investigate the characteristics of the spatiotemporal variations of the $E_{p a n}$ of the HRB both in a basin scale and a single test station scale under the background of climatic change. Another one is to verify the infection years of $E_{p a n}$ and to find out whether the pan evaporation paradox exists in a particular transitional region such as the HRB.

\section{Materials and methods}

\section{Study area}

The HRB is located in the middle of China, between the east and north China plain climate regions $\left(111^{\circ} 55^{\prime} \mathrm{E}-121^{\circ} 25^{\prime} \mathrm{E}\right.$ and $\left.30^{\circ} 55^{\prime} \mathrm{N}-36^{\circ} 36^{\prime} \mathrm{N}\right)$. The basin area is approximately $270,000 \mathrm{~km}^{2}$. The west, southwest and northeast of the basin are mountainous and hilly areas, accounting for about $1 / 3$ of the total basin area. The rest are vast plains (Fig. 1). Qinling Mountains-Huaihe River Line is an important geographical (landform, climate, soil) line in China. The north of this line is characterized by both the warm temperate continental climate and the semi-humid monsoon climate, while the south of it is humid subtropical monsoon climate zone. Therefore, the HRB has the obvious characteristics of north-to-south and land-to-sea transition because the east of the basin is close to the sea. The HRB has a unique topography and diverse climate characteristics, which is a suitable watershed for studying the hydrological cycle process and the evolution of hydrological factors. 


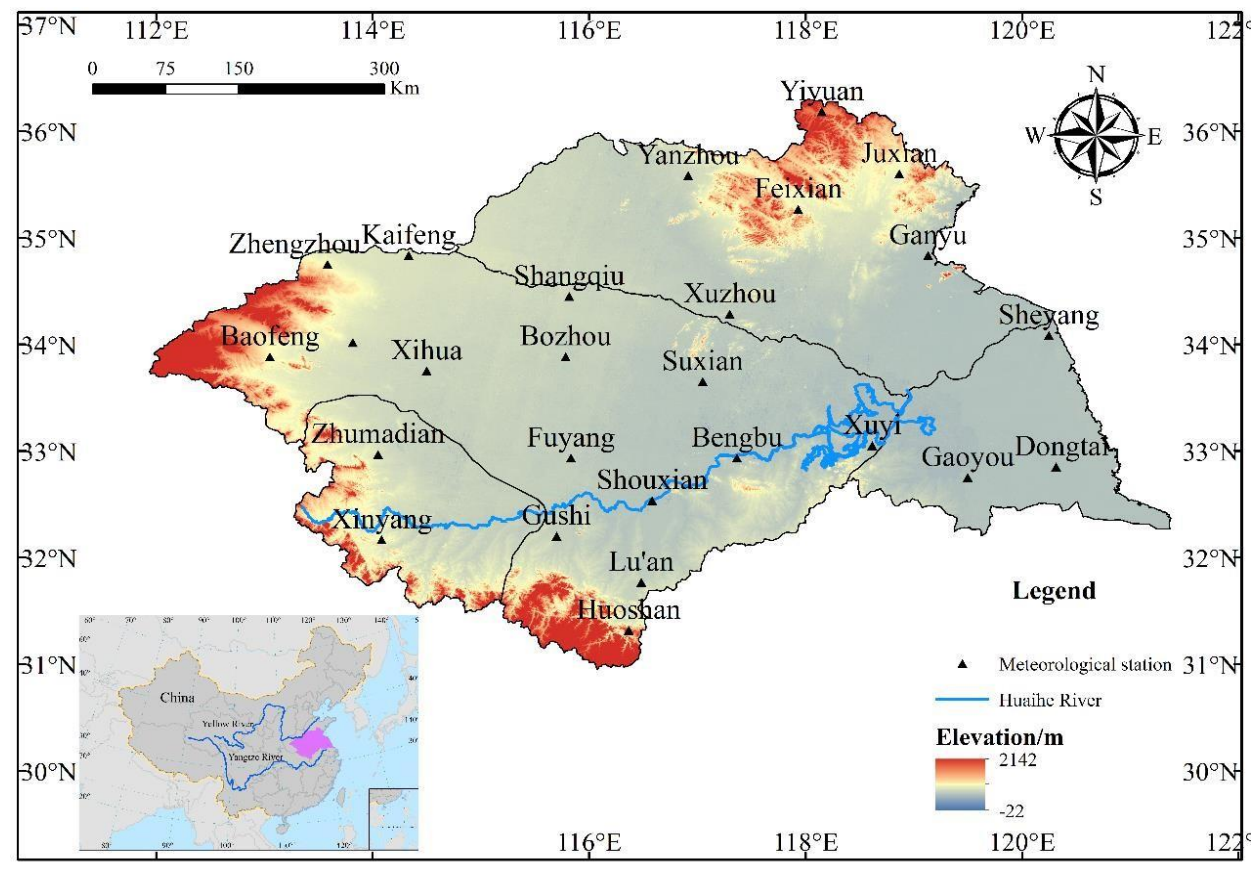

Figure 1. Map of the Huaihe River Basin

\section{Data}

Daily $E_{p a n}$ and $T_{a}$ data of 26 evenly distributed meteorological stations in the HRB were selected for the study. Table 1 shows the sites location and data series information. Data were downloaded from the China Meteorological Data Network (http://data.cma.cn/site/index.html) and have been subjected to strict homogenization quality control. Before $1990 \mathrm{~s}, \mathrm{E}_{\mathrm{pan}}$ in China was measured by D20 pans, the pans are made of copper with a diameter of $20 \mathrm{~cm}$ and depth of $10 \mathrm{~cm}$. They are installed $70 \mathrm{~cm}$ above the ground and have rims to prevent birds from drinking. The D20 pans are smaller and hold less water compared with Class A pans which are popular in the USA. After 2001, the evaporation pans are gradually changed into E601 pans. They consist of an evaporator, a water circle, an overflow barrel and a needle, and installed near the D20 pans. The pan area is $3000 \mathrm{~cm}^{2}$ and the water circle is installed on the periphery of evaporator barrel, the inside and outside wall height is $13.7 \mathrm{~cm}$ and $15.0 \mathrm{~cm}$ respectively. Compared with the D20 pan, the E601 pan is more reasonable and scientific because of its instrument structure, installation height and surrounding environment, so the evaporation it measured is more representative to the condition of the natural water surface.

Table 1. Characteristics of the meteorological stations selected for this study

\begin{tabular}{c|c|c|c|c|c|c}
\hline \multirow{2}{*}{ No. } & \multirow{2}{*}{ Station } & \multirow{2}{*}{ Longitude E/ } & \multirow{2}{*}{ Latitude N/o } & \multirow{2}{*}{ Elevation/m } & \multicolumn{2}{|c}{ Period } \\
\cline { 6 - 7 } & & & & & D20 pans & E601 pans \\
\hline 1 & Yiyuan & 118.15 & 36.18 & 304.5 & $1958-2001$ & $1998-2015$ \\
2 & Yanzhou & 116.92 & 35.58 & 51.0 & $1952-2001$ & $1998-2015$ \\
3 & Feixian & 117.93 & 35.27 & 109.8 & $1959-2001$ & $1998-2015$ \\
4 & Juxian & 118.87 & 35.60 & 86.4 & $1952-2001$ & $1988-2015$ \\
5 & Zhengzhou & 113.58 & 34.75 & 80.6 & $1951-2001$ & $1985-2015$ \\
6 & Xuchang & 113.82 & 34.02 & 68.0 & $1952-2001$ & $1998-2015$
\end{tabular}




\begin{tabular}{c|c|c|c|c|c|c}
7 & Kaifeng & 114.33 & 34.83 & 75.0 & $1951-2001$ & $1998-2015$ \\
8 & Baofeng & 113.05 & 33.88 & 135.1 & $1957-2001$ & $1998-2015$ \\
9 & Xihua & 114.50 & 33.75 & 51.3 & $1953-2001$ & $1999-2015$ \\
10 & Zhuamadian & 114.05 & 32.97 & 78.8 & $1958-2001$ & $1998-2015$ \\
11 & Xinyang & 114.08 & 32.17 & 74.0 & $1951-2001$ & $1985-2015$ \\
12 & Shangqiu & 115.82 & 34.45 & 50.1 & $1953-2001$ & $1985-2015$ \\
13 & Xuzhou & 117.30 & 34.28 & 43.0 & $1960-2001$ & $1984-2015$ \\
14 & Ganyu & 119.13 & 34.83 & 2.1 & $1957-2001$ & $1998-2015$ \\
15 & Bozhou & 115.78 & 33.88 & 37.6 & $1953-2001$ & $1998-2015$ \\
16 & Suxian & 117.05 & 33.65 & 28.0 & $1952-2001$ & $1987-2015$ \\
17 & Xuyi & 118.62 & 33.05 & 13.4 & $1957-2001$ & $1999-2015$ \\
18 & Sheyang & 120.25 & 34.08 & 1.6 & $1954-2001$ & $1998-2015$ \\
19 & Fuyang & 115.83 & 32.93 & 33.3 & $1953-2001$ & $1998-2015$ \\
20 & Gushi & 115.70 & 32.20 & 40.4 & $1952-2001$ & $1998-2015$ \\
21 & Shouxian & 116.58 & 32.53 & 23.3 & $1955-2001$ & $1993-2015$ \\
22 & Bengbu & 117.37 & 32.93 & 20.6 & $1952-2001$ & $1998-2015$ \\
23 & Gaoyou & 119.50 & 32.75 & 6.4 & $1958-2001$ & $1998-2015$ \\
24 & Dongtai & 120.32 & 32.85 & 5.8 & $1953-2001$ & $1998-2015$ \\
25 & Lu'an & 116.48 & 31.77 & 39.5 & $1955-2001$ & $1998-2015$ \\
26 & Huoshan & 116.37 & 31.32 & 91.9 & $1954-2001$ & $1998-2015$ \\
\hline
\end{tabular}

\section{Data processing}

The $E_{p a n}$ series of each station during 1951-2015 were measured from two different types of evaporation pans, hence data processing is required. As shown by Table 1, for each site of the HRB, the length of data series from the D20 pans is longer than that from the E601 pans, while there also exist synchronous observations of the two types of pans. In order to eliminate the influence of data conversion on the following study, we converted data from the E601 pans into the D20 pans to get 65-year data series of all sites by building functions between the synchronous observation data of the two kinds of pans.

Figure 2 shows the correlations between the $\mathrm{E}_{\mathrm{pan}}$ of two pans in three representative meteorological stations, which are Bozhou station (4-year synchronous observations), Shouxian station (9-year synchronous observations) and Suxian station (15-year synchronous observations). There exist linear correlations between the three different periods of synchronous data of two pans because each of the correlation coefficient is greater than 0.9 .
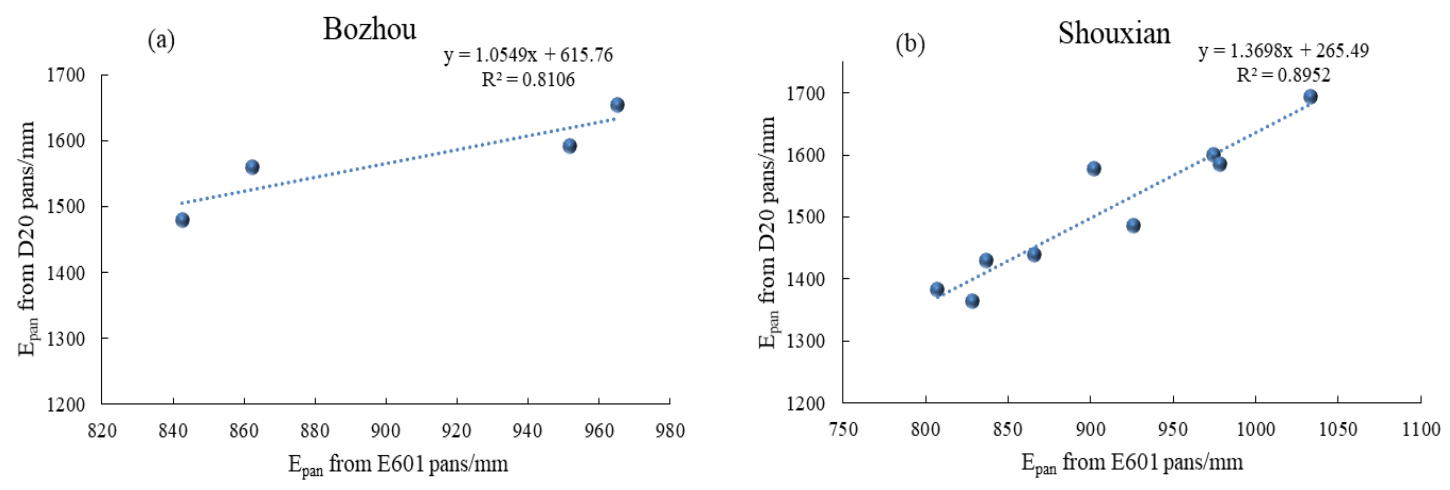


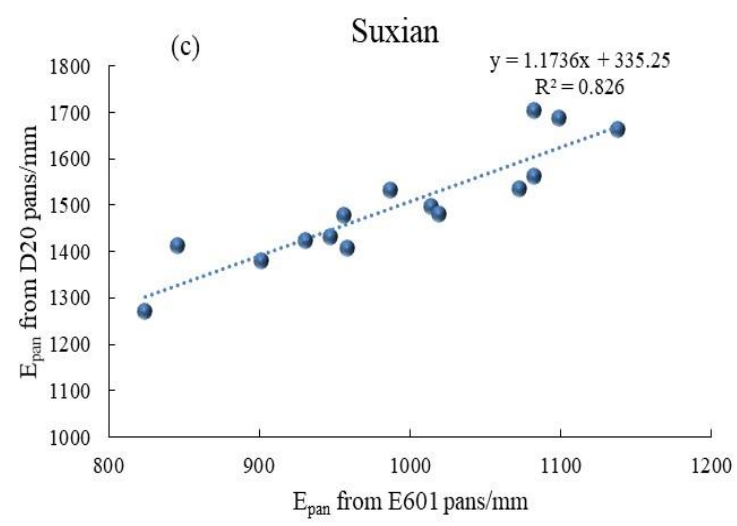

Figure 2. Scatter plots between $E_{\text {pan }}$ observed by the D20 pans and E601 pans in the three representative stations

Relative error is calculated by Equations 1 and 2:

$$
\begin{gathered}
y_{1}=a x_{0}+b \\
\delta=\frac{\left|y_{1}-y_{0}\right|}{y_{0}} \times 100 \%
\end{gathered}
$$

where $x_{0}$ is the $\mathrm{E}_{\mathrm{pan}}$ observed from E601 pans, $y_{0}$ is the $\mathrm{E}_{\mathrm{pan}}$ observed from D20 pans, $y_{1}$ is the converted $\mathrm{D} 20 \mathrm{E}_{\mathrm{pan}}$, and $\delta$ is the relative error.

Table 2 illustrates the conversion results of the two types of $\mathrm{E}_{\mathrm{pan}}$. As can be seen from the table, the average relative error of all sites is $2.2 \%$, and the relative error of a single site is less than $5.4 \%$. Overall, the correlations between the two types of $\mathrm{E}_{\text {pan }}$ suggest that the regression functions shown in Table 2 can be used for data conversion after 2001. Figure 3 presents the data conversion results of the three representative stations mentioned above.

\section{Methods}

In this study, we determined the spatial distribution of average annual $E_{p a n}$ and $T_{a}$ of the HRB by using the inverse distance weighted (IDW) method. The variation trends of $\mathrm{E}_{\mathrm{pan}}$ and $\mathrm{T}_{\mathrm{a}}$ were analyzed by using linear regression approach, and the relationship between them was detected by examining the correlation coefficient.

Table 2. Error analysis and conversion functions of the two types of $E_{p a n}$.

\begin{tabular}{c|c|c|c}
\hline No. & Station & Conversion functions & Relative error (\%) \\
\hline 1 & Yiyuan & $\mathrm{y}=0.4919 \mathrm{x}+1097.4$ & 0.44 \\
2 & Yanzhou & $\mathrm{y}=1.8617 \mathrm{x}+35.436$ & 3.60 \\
3 & Feixian & $\mathrm{y}=2.1671 \mathrm{x}-525.43$ & 0.32 \\
4 & Juxian & $\mathrm{y}=1.1621 \mathrm{x}+191.7$ & 2.38 \\
5 & Zhengzhou & $\mathrm{y}=0.2946 \mathrm{x}+1416.5$ & 2.18 \\
6 & Xuchang & $\mathrm{y}=0.56 \mathrm{x}+987.28$ & 1.91
\end{tabular}




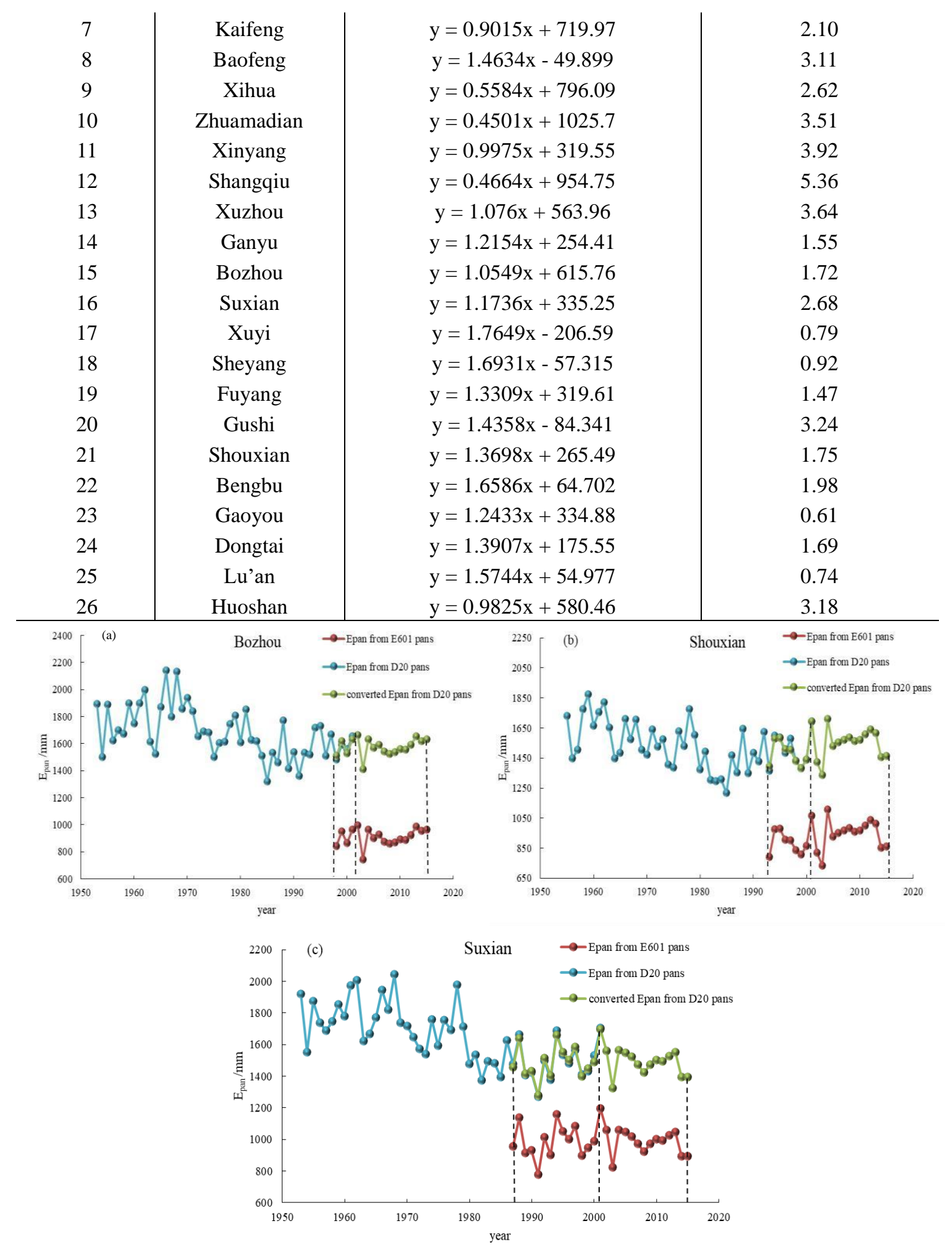

Figure 3. Data conversion results of the representative stations 


\section{Results}

\section{Spatial distribution of the average $E_{p a n}$ of the HRB}

The average annual $\mathrm{E}_{\mathrm{pan}}$ and $\mathrm{T}_{\mathrm{a}}$ of 26 meteorological stations were calculated, and the spatial distributions of them are shown in Figure 4.

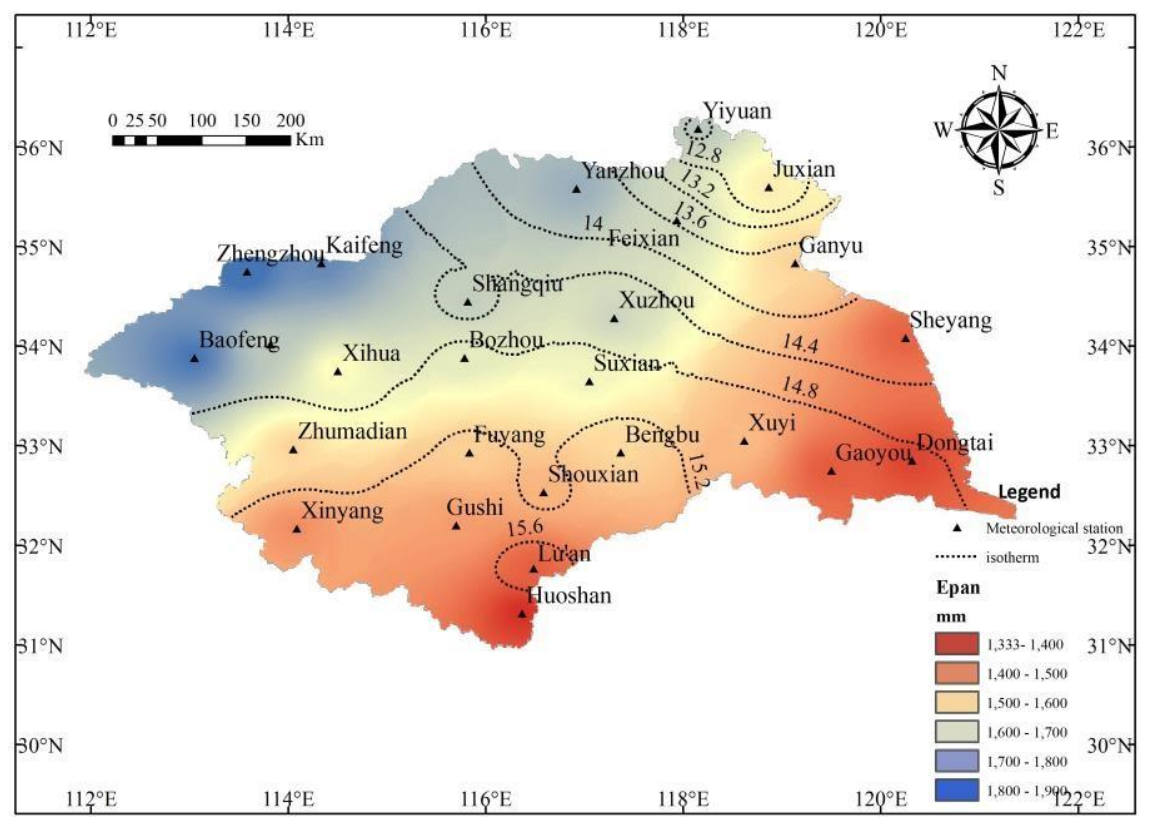

Figure 4. Spatial distributions of $E_{p a n}$ and $T_{a}$ in the $H R B$

According to Figure 4, we can draw the following two conclusions:

(1) The average annual $E_{p a n}$ of the $H R B$ features significant spatial variability, showing an obvious zoning characteristic and increasing gradually from southeast to northwest, from coastal area to inland, and from the humid area to semi-humid area. The maximum $\mathrm{E}_{\mathrm{pan}}$ appears in the northwestern part of the HRB around Baofeng, Zhengzhou and Kaifeng, which is up to $1800 \mathrm{~mm}$. The minimum appears in the eastern coast around Gaoyou, Dongtai and the southernmost Huoshan station of the basin, which is about $1400 \mathrm{~mm}$.

(2) According to the isotherm (i.e., the dotted lines in Figure 4), it can be seen that the trend of $\mathrm{T}_{\mathrm{a}}$ is not consistent with $\mathrm{E}_{\mathrm{pan}}$, and the $\mathrm{T}_{\mathrm{a}}$ increases gradually from northeast to southwest, and the maximum value appears in Lu'an station. Around Xinyang, Gushi, Lu'an and Huoshan station, onthe right bank of the Huaihe River andin the southern part of the basin. $T_{a}$ reaches the highest and $E_{p a n}$ reaches the lowest at the same time. The results show that the $E_{p a n}$ is not completely consistent with the $T_{a}$ because it is affected by other factors besides the $T_{a}$.

\section{Variation of the average $E_{p a n}$ of the $H R B$}

\section{Variation within the year}

The average annual $\mathrm{E}_{\mathrm{pan}}$ of the HRB is $1565 \mathrm{~mm}$ and portrays a single peak curve of the whole year. Figure 5 presents the average monthly $\mathrm{E}_{\mathrm{pan}}$ and $\mathrm{T}_{\mathrm{a}}$. It shows that the peak of the $E_{p a n}$ curve occurs in June with a value of $220.7 \mathrm{~mm}$, accounting for $14.1 \%$ of the year. The $\mathrm{E}_{\mathrm{pan}}$ of May and July follow after, accounting for $13.0 \%$ and $12.2 \%$, 
respectively. The minimum appears in January with a value of $49.1 \mathrm{~mm}$, accounting for merely $3.1 \%$. Changes of $\mathrm{T}_{\mathrm{a}}$ and $\mathrm{E}_{\mathrm{pan}}$ within the year are similar but they are not completely synchronous. The peak of $\mathrm{T}_{\mathrm{a}}$ occurs later than $\mathrm{E}_{\mathrm{pan}}$, and $\mathrm{T}_{\mathrm{a}}$ peaks at $27.2{ }^{\circ} \mathrm{C}$ in July and bottoms out at $0.6{ }^{\circ} \mathrm{C}$ in January, indicating that $\mathrm{T}_{\mathrm{a}}$ is not the unique climatic factor affecting $\mathrm{E}_{\mathrm{pan}}$.

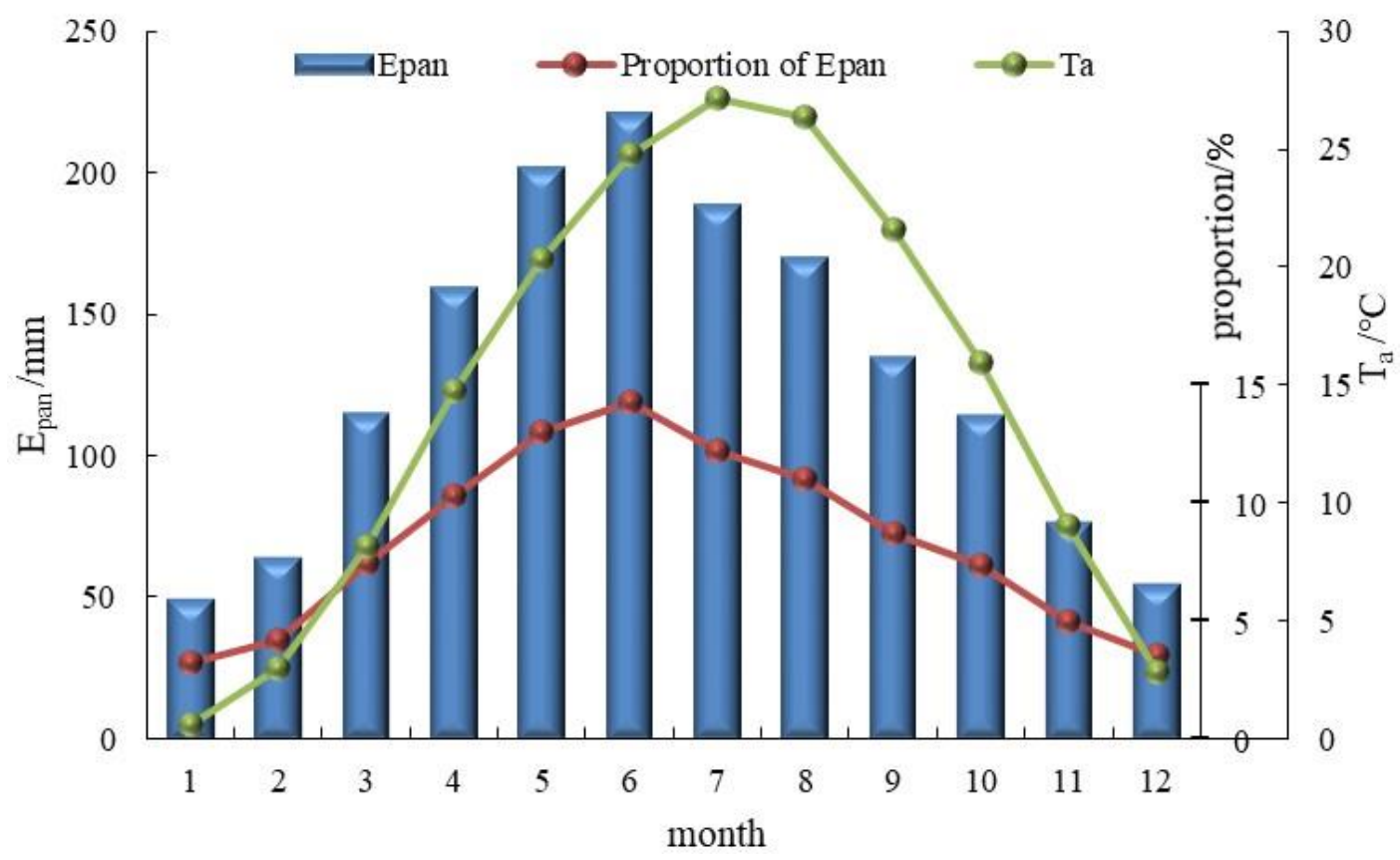

Figure 5. The average monthly $E_{p a n}$ and $T_{a}$ in the $H R B$

It can be inferred that the reasons of the $E_{\text {pan }}$ change are as following: in January, February and December, the $T_{a}$ of the basin is relatively low and the surface is sometimes covered with snow and ice, which hinders evaporation from vegetation and soil (Ruosteenoja et al., 2017). From March to May, ice and snow start to melt as $\mathrm{T}_{\mathrm{a}}$ slowly increases, resulting in a gradually increasing trend of $\mathrm{E}_{\mathrm{pan}}$. From June to August, the $\mathrm{T}_{\mathrm{a}}$ reaches its maximum value of the year, creating the most favorable situation for evaporation with abundant sunshine and high wind speed, and $E_{\text {pan }}$ reaches its peak in June. From September to November, the $T_{a}$ decreases slowly and changes towards the unfavorable situation for evaporation and the $\mathrm{E}_{\mathrm{pan}}$ of this period begins to decrease as a result.

Table 3 lists the average $\mathrm{E}_{\mathrm{pan}}$ of four seasons and their proportions. It can be seen that the $\mathrm{E}_{\mathrm{pan}}$ in summer is the largest, and the $\mathrm{E}_{\mathrm{pan}}$ in spring and summer account for nearly $68.4 \%$ of the annual $\mathrm{E}_{\mathrm{pan}}$ while the $\mathrm{E}_{\mathrm{pan}}$ in winter is the smallest, which merely accounts for $10.8 \%$ of the annual value. Therefore, the $\mathrm{E}_{\mathrm{pan}}$ in spring and summer play an important role in the water cycle.

Table 3. Average seasonal $E_{p a n}$ and their proportions of the year

\begin{tabular}{c|c|c}
\hline Season & $\mathbf{E}_{\mathbf{p a n}} / \mathbf{m m}$ & Proportion/\% \\
\hline Spring (March to May) & 476 & 30.4 \\
Summer (June to August) & 594 & 38.0
\end{tabular}


Autumn (September to November)

Winter (December to February)
20.8

10.8

\section{Variation among years}

Figure 6 shows the variations of average annual $\mathrm{E}_{\mathrm{pan}}$ and $\mathrm{T}_{\mathrm{a}}$ including the six-year moving average of $E_{p a n}$ of the HRB. It indicates that the annual $E_{p a n}$ fitting curve firstly increases then decreases and finally flattens, showing that the $\mathrm{E}_{\mathrm{pan}}$ has a clear upward trend before the mid-1960s. After that period it decreases, and at last moves into a much smaller fluctuation state in the late 1980s. Therefore, we regarded the highest point (1966) and lowest point (1985) of the $\mathrm{E}_{\text {pan }}$ process as turning points, as well as analyzing the variation of the average annual $E_{\mathrm{pan}}$ of the $\mathrm{HRB}$ and drawing the following conclusions.

(1) The 65-year series from 1951 to 2015 can be divided into three periods. The 1951-1966 period shows a fluctuated increasing trend at a rate of about $257.3 \mathrm{~mm}$ per decade with a significance level of 0.05 and reaches its maximum in 1966. The 19671985 period presents a fluctuated downward trend at the rate of $-195.2 \mathrm{~mm} / 10 \mathrm{a}$ with a significance level of 0.01 and reaches its minimum in 1985. The 1986-2015 period portrays a non-significant increasing trend again but the rate is much smaller than that before 1966 (i.e., merely $12.8 \mathrm{~mm} / 10 \mathrm{a}$ ).

(2) From the variation of average $T_{a}$ of the HRB, it can be found that during 19511966, the $T_{a}$ fluctuates but has an increasing trend with the amplitude of $0.76{ }^{\circ} \mathrm{C}$ every decade with a significance level of 0.05. During 1967-1985, the rising of $\mathrm{T}_{\mathrm{a}}$ slows down with a non-significant rate of $0.05{ }^{\circ} \mathrm{C} / 10 \mathrm{a}$. The warming trend in the HRB becomes significant again and the upward rate is $0.36{ }^{\circ} \mathrm{C}$ every 10 years with a significance level of 0.01 after 1985.

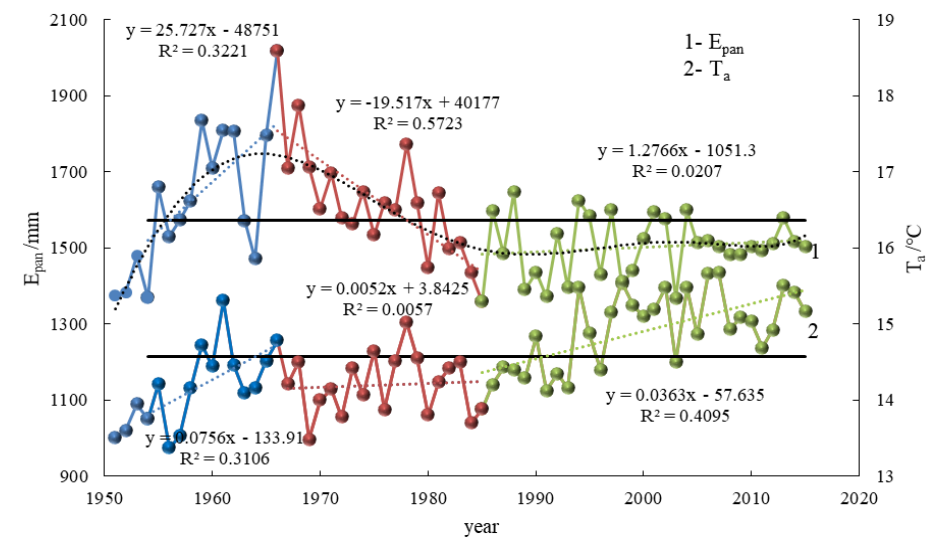

Figure 6. Variations of the average annual $E_{p a n}$ and $T_{a}$ in the HRB (the dotted curve is the sixyear moving average of $E_{p a n}$, the dotted lines represent the linear trends fitted to the corresponding periods)

(3) Figure 7 illustrates the relationships between variations of $E_{p a n}$ and $T_{a}$ during different periods. The $T_{a}$ and $E_{p a n}$ in the period of 1967-1985 vary inversely as the $T_{a}$ increases while $\mathrm{E}_{\mathrm{pan}}$ decreases, thus during this period there exists the so-called pan evaporation paradox. In the other two periods, the $\mathrm{T}_{\mathrm{a}}$ and $\mathrm{E}_{\mathrm{pan}}$ are positively correlated 
as they both show increasing trends. As a result, pan evaporation paradox does not exist. The trend of $\mathrm{E}_{\mathrm{pan}}$ is not always consistent with that of $\mathrm{T}_{\mathrm{a}}$ from 1951 to 2015, indicating that $\mathrm{T}_{\mathrm{a}}$ is not the unique factor affecting $\mathrm{E}_{\mathrm{pan}}$. It deserves to be further studied on the attribution of $\mathrm{E}_{\mathrm{pan}}$ change.

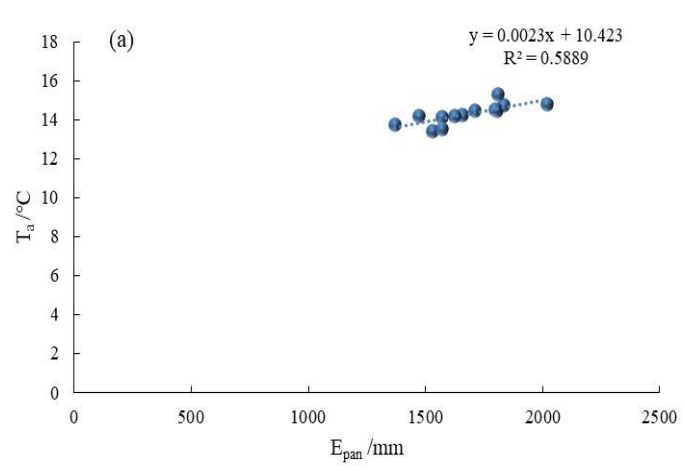

(a) 1951-1966

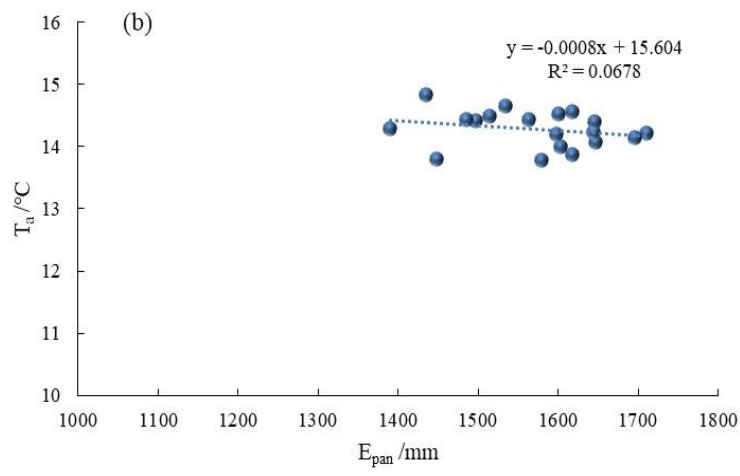

(b) 1967-1985

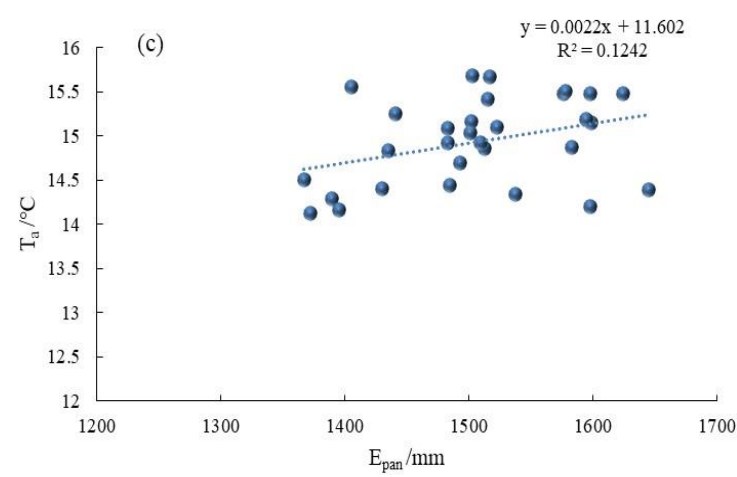

(c) 1986-2015

Figure 7. Scatter plots between $E_{p a n}$ and $T_{a}$ of the HRB during different periods

Figure 8 shows the seasonal variations of $\mathrm{E}_{\mathrm{pan}}$. Table 4 lists the change points, the evaporative rates and significance levels of average annual and seasonal $\mathrm{E}_{\mathrm{pan}}$. As can be seen, the variations of the four seasons and the whole year are basically the same. The first change points of the four seasons are around 1966, and the second are around 1985. Spring shows the largest increasing trend in the first period, which is $188.0 \mathrm{~mm} / 10 \mathrm{a}$, summer shows the largest decreasing trend for about $-95.2 \mathrm{~mm} / 10 \mathrm{a}$ in the second period. Trends of the third period are not obvious, with spring, summer and winter showing non-significant upward trends while autumn showing a slight downward trend. Therefore, the $\mathrm{E}_{\mathrm{pan}}$ in spring and summer contributes the most to the significant increase and decrease period of annual $E_{\text {pan }}$ separately, and the comprehensive effect of the four seasons results in a non-significant upward trend of annual $\mathrm{E}_{\mathrm{pan}}$ after 1985. 




(a) Spring

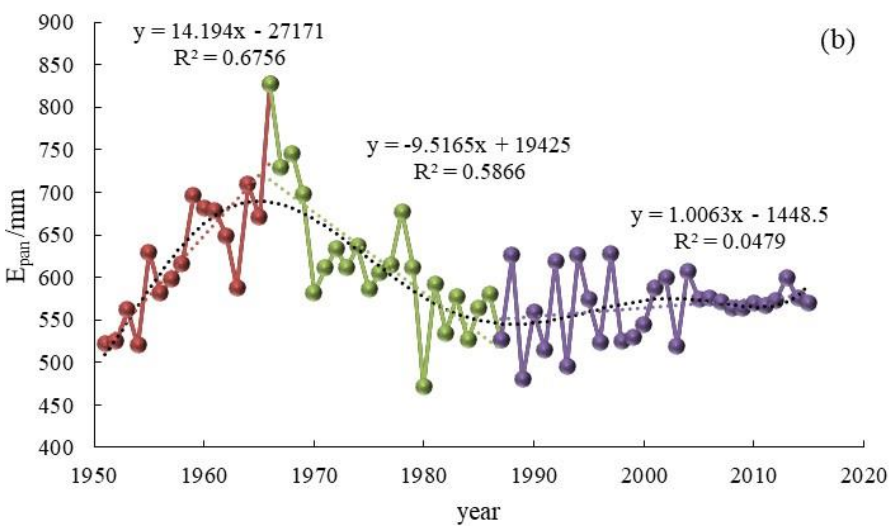

(b) Summer

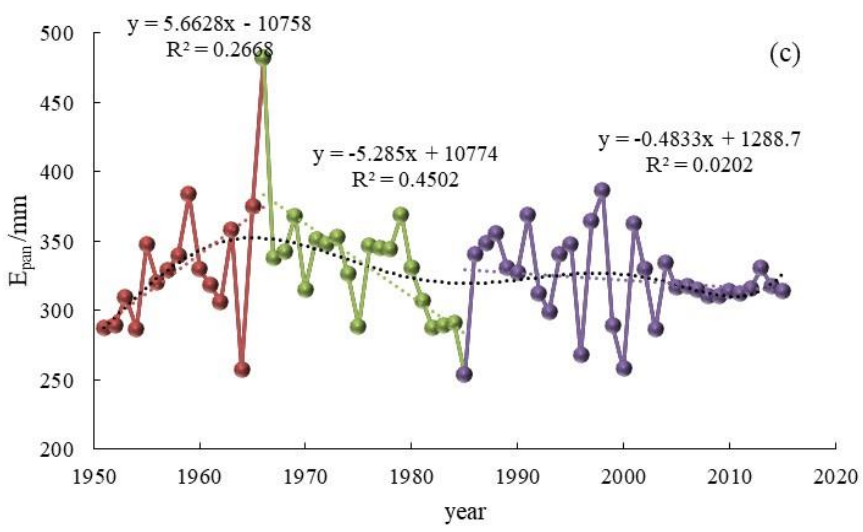

(c) Autumn

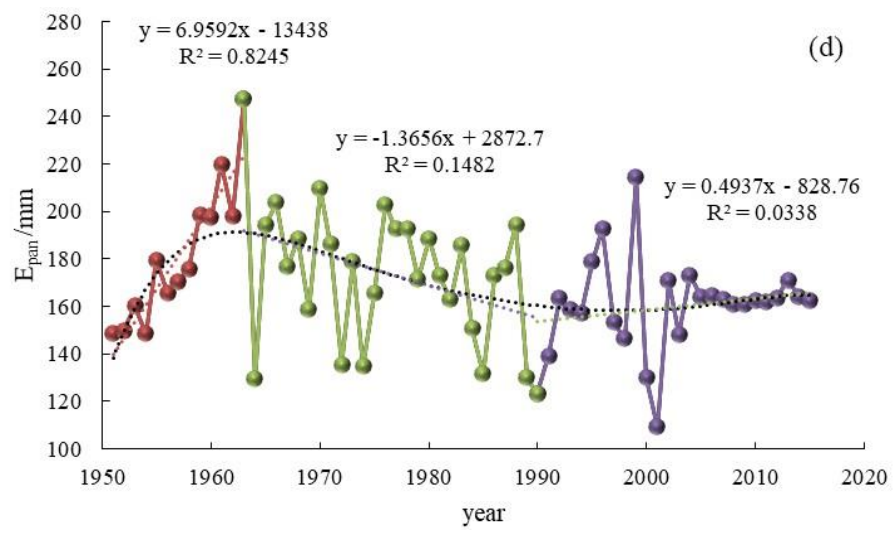

(d) Winter 
Figure 8. Variations of the average $E_{\text {pan }}$ of different seasons of the HRB

Table 4. Change points, evaporative rates and significance levels of average annual and seasonal $E_{\text {pan }}$ of the HRB

\begin{tabular}{|c|c|c|c|c|c|c|c|c|}
\hline \multirow[b]{2}{*}{ Period } & \multirow[b]{2}{*}{$\begin{array}{c}\text { 1st change } \\
\text { point }\end{array}$} & \multirow[b]{2}{*}{$\begin{array}{c}\text { 2nd change } \\
\text { point }\end{array}$} & \multicolumn{3}{|c|}{ Evaporative rate $(\mathbf{m m} / \mathbf{1 0 a})$} & \multicolumn{3}{|c|}{ Significance level } \\
\hline & & & $\begin{array}{c}1_{\text {st }} \\
\text { period }\end{array}$ & $\begin{array}{c}\text { 2nd } \\
\text { period }\end{array}$ & $\begin{array}{c}\text { 3rd } \\
\text { period }\end{array}$ & $\begin{array}{c}\text { 1st } \\
\text { period }\end{array}$ & $\begin{array}{c}\text { 2nd } \\
\text { period }\end{array}$ & $\begin{array}{c}\text { 3rd } \\
\text { period }\end{array}$ \\
\hline Spring & 1962 & 1991 & 188.0 & -31.9 & 11.5 & 0.01 & 0.05 & l \\
\hline Summer & 1966 & 1987 & 141.9 & -95.2 & 10.1 & 0.01 & 0.01 & l \\
\hline Autumn & 1966 & 1985 & 56.6 & -52.9 & -4.8 & 0.05 & 0.01 & l \\
\hline Winter & 1963 & 1990 & 69.6 & -13.7 & 4.9 & 0.01 & 0.05 & l \\
\hline Annual & 1966 & 1985 & 257.3 & -195.2 & 12.8 & 0.05 & 0.01 & l \\
\hline
\end{tabular}

"/" represents being non-significant at the significance level of 0.05

\section{Variation of $E_{p a n}$ of a single site}

The long-term changes of $\mathrm{E}_{\mathrm{pan}}$ of the 26 meteorological stations were analyzed. The $\mathrm{E}_{\mathrm{pan}}$ of a single station is not consistent with each other, but the clustering characteristics of them are obvious, which can be divided into two categories as below.

(1) The variations of $E_{p a n}$ of 24 sites are basically the same as that of the watershed average which has three obvious changing periods (Fig. 9). They all show increasing trends from 1951 to 1966 and significant decreasing trends from 1967 to 1985 except for Xuyi station. However, there are some differences in the $\mathrm{E}_{\mathrm{pan}}$ changes during 19862015 (segmented analytical results are shown in Tables 5-7).

There are 12 stations showing non-significant increasing trends (the forms of their process are similar to Gushi station and Sheyang station shown in Fig. 9). Although 7 stations show decreasing trends, the slopes of them are much smaller (the forms are similar to Baofeng station and Yanzhou station shown in Fig. 9). The slopes of $E_{\text {pan }}$ trends in Baofeng station and Yanzhou station decrease from $-346 \mathrm{~mm} / 10 \mathrm{a}$ and -274 $\mathrm{mm} / 10 \mathrm{a}$ in $1967-1985$ to $-32 \mathrm{~mm} / 10 \mathrm{a}$ and $-31 \mathrm{~mm} / 10 \mathrm{a}$, decreasing by $91 \%$ and $89 \%$. There are also 5 stations showing increasing trends with a significance level of 0.05 (the forms are similar to Shangqiu station and Fuyang station shown in Fig. 9). 



Figure 9. Variations of the average annual $E_{\text {pan }}$ of the first category (partly)

Table 5. Trend analysis of the average $E_{p a n}$ of the HRB during 1951-1966

\begin{tabular}{c|c|c|c|c}
\hline No. & Station & Correlation coefficient/R & Evaporative rate $(\mathbf{m m} / \mathbf{1 0 a})$ & Significance level \\
\hline 1 & Bengbu & 0.65 & 346.8 & 0.01 \\
2 & Dongtai & 0.55 & 152.3 & 0.05 \\
3 & Juxian & 0.49 & 226.3 & 0.05 \\
4 & Feixian & 0.52 & 165.4 & 0.05 \\
5 & Gushi & 0.27 & 118.1 & $/$ \\
6 & Sheyang & 0.85 & 291.1 & 0.01 \\
7 & Xihua & 0.31 & 200.6 & $/$ \\
8 & Zhengzhou & 0.49 & 353.1 & 0.05 \\
9 & Xinyang & 0.68 & 198.1 & 0.01 \\
10 & Zhumadian & 0.17 & 150.6 & $/$
\end{tabular}




\begin{tabular}{l|c|c|c|c}
11 & Lu'an & 0.06 & 21.7 & $/$ \\
12 & Huoshan & 0.67 & 234.7 & 0.01 \\
13 & Baofeng & 0.35 & 361.2 & $/$ \\
14 & Xuzhou & 0.34 & 99.7 & $/$ \\
15 & Yanzhou & 0.29 & 111.3 & $/$ \\
16 & Xuchang & 0.59 & 428.8 & 0.05 \\
17 & Yiyuan & 0.25 & 161.7 & $/$ \\
18 & Ganyu & 0.37 & 173.5 & $/$ \\
19 & Xuyi & 0.24 & $/$ \\
20 & Bozhou & 0.29 & 130.7 & $/$ \\
21 & Kaifeng & 0.31 & 269.2 & 0.05 \\
22 & Shangqiu & 0.45 & 289.9 & 0.05 \\
23 & Fuyang & 0.60 & 323.7 & $/$ \\
24 & Suxian & 0.15 & 48.2 & \\
\hline
\end{tabular}

Table 6. Trend analysis of the average $E_{\text {pan }}$ of the HRB during 1967-1985

\begin{tabular}{c|c|c|c|c}
\hline No. & Station & Correlation coefficient/R & Evaporative rate $(\mathbf{m m} / \mathbf{1 0 a})$ & Significance level \\
\hline 1 & Bengbu & -0.47 & -166.9 & 0.05 \\
2 & Dongtai & -0.44 & -113.8 & 0.10 \\
3 & Juxian & -0.72 & -188.3 & 0.01 \\
4 & Feixian & -0.70 & -367.1 & 0.01 \\
5 & Gushi & -0.74 & -245.7 & 0.01 \\
6 & Sheyang & -0.72 & -177.7 & 0.01 \\
7 & Xihua & -0.81 & -263.6 & 0.01 \\
8 & Zhengzhou & -0.76 & -334.3 & 0.01 \\
9 & Xinyang & -0.85 & -464.1 & 0.01 \\
10 & Zhumadian & -0.63 & -192.6 & 0.01 \\
11 & Lu'an & -0.69 & -199 & 0.01 \\
12 & Huoshan & -0.63 & -143.2 & 0.01 \\
13 & Baofeng & -0.86 & -346.2 & 0.01 \\
14 & Xuzhou & -0.84 & -368.9 & 0.01 \\
15 & Yanzhou & -0.92 & -274.2 & 0.01 \\
16 & Xuchang & -0.83 & -434.9 & 0.01 \\
17 & Yiyuan & -0.67 & -188.3 & 0.01 \\
18 & Ganyu & -0.61 & -122.1 & 0.01 \\
19 & Xuyi & -0.29 & -57.5 & $/$ \\
20 & Bozhou & -0.73 & -247.4 & 0.01 \\
21 & Kaifeng & -0.80 & -403.4 & 0.01 \\
22 & Shangqiu & -0.87 & -346.3 & 0.01 \\
23 & Fuyang & -0.81 & -363.9 & 0.01 \\
24 & Suxian & -0.70 & -222.4 & 0.01 \\
\hline
\end{tabular}


Table 7. Trend analysis of the average $E_{p a n}$ of the HRB during 1986-2015

\begin{tabular}{c|c|c|c|c}
\hline No. & Station & Correlation coefficient/R & Evaporative rate $(\mathbf{m m} / \mathbf{1 0 a})$ & $\begin{array}{l}\text { Significance } \\
\text { level }\end{array}$ \\
\hline 1 & Bengbu & 0.23 & 25.7 & $/$ \\
2 & Dongtai & 0.24 & 23.2 & $/$ \\
3 & Juxian & 0.25 & 23.3 & $/$ \\
4 & Feixian & 0.34 & 42.1 & $/$ \\
5 & Gushi & 0.22 & 28.4 & $/$ \\
6 & Sheyang & 0.34 & 38.7 & $/$ \\
7 & Xihua & 0.07 & 7.9 & $/$ \\
8 & Zhengzhou & 0.02 & 2.6 & $/$ \\
9 & Xinyang & 0.16 & 20.9 & $/$ \\
10 & Zhumadian & 0.17 & 26 & $/$ \\
11 & Lu'an & 0.26 & 26.9 & $/$ \\
12 & Huoshan & 0.02 & 2.3 & $/$ \\
13 & Baofeng & -0.34 & -47.3 & $/$ \\
14 & Xuzhou & -0.31 & -34.5 & $/$ \\
15 & Yanzhou & -0.28 & -37.7 & $/$ \\
16 & Xuchang & -0.35 & -42.1 & $/$ \\
17 & Yiyuan & -0.28 & -30.6 & $/$ \\
18 & Ganyu & -0.31 & -45.7 & 0.05 \\
19 & Xuyi & -0.09 & -10 & 0.05 \\
20 & Bozhou & 0.38 & 44.3 & 0.05 \\
21 & Kaifeng & 0.44 & 54.3 & 0.05 \\
22 & Shangqiu & 0.65 & 85.8 & 0.05 \\
23 & Fuyang & 0.65 & 104.4 & \\
24 & Suxian & 0.44 & 54 & $/$ \\
\hline
\end{tabular}

(2) The long-term changes of $\mathrm{E}_{\mathrm{pan}}$ in Gaoyou station and Shouxian station are both divided into two obvious periods by the year of 1985 (Fig. 10). Table 8 shows the trends of $E_{p a n}$ before and after 1985. As it shows, before 1985, the $E_{p a n}$ of both two stations decrease significantly at a level of 0.05 in Gaoyou station and 0.01 in Shouxian station. After 1985, the $\mathrm{E}_{\text {pan }}$ of Gaoyou station still shows a downward trend but the slope of it is smaller than before, decreasing from $-50.2 \mathrm{~mm} / 10 \mathrm{a}$ to $-27.4 \mathrm{~mm} / 10 \mathrm{a}$, which is not statistically significant at a level of 0.05 . However, the $\mathrm{E}_{\mathrm{pan}}$ of Shouxian station shows a rising trend inversely with the evaporative rate turning from $115.6 \mathrm{~mm} / 10 \mathrm{a}$ to 50.3 $\mathrm{mm} / 10 \mathrm{a}$ and is statistically significant at a level of 0.05 .

Table 8. Comparison between the trends of the average annual $E_{p a n}$ of the second category before and after 1985

\begin{tabular}{c|c|c|c|c|c|c}
\hline \multirow{2}{*}{ Station } & \multicolumn{2}{|c|}{ Correlation coefficient /R } & \multicolumn{2}{c|}{ Evaporative rate (mm/10a) } & \multicolumn{2}{c}{ Significance level } \\
\cline { 2 - 7 } & Before 1985 & After 1985 & Before 1985 & After 1985 & Before 1985 & After 1985 \\
\hline Gaoyou & -0.41 & -0.27 & -50.2 & -27.4 & 0.05 & $/$
\end{tabular}




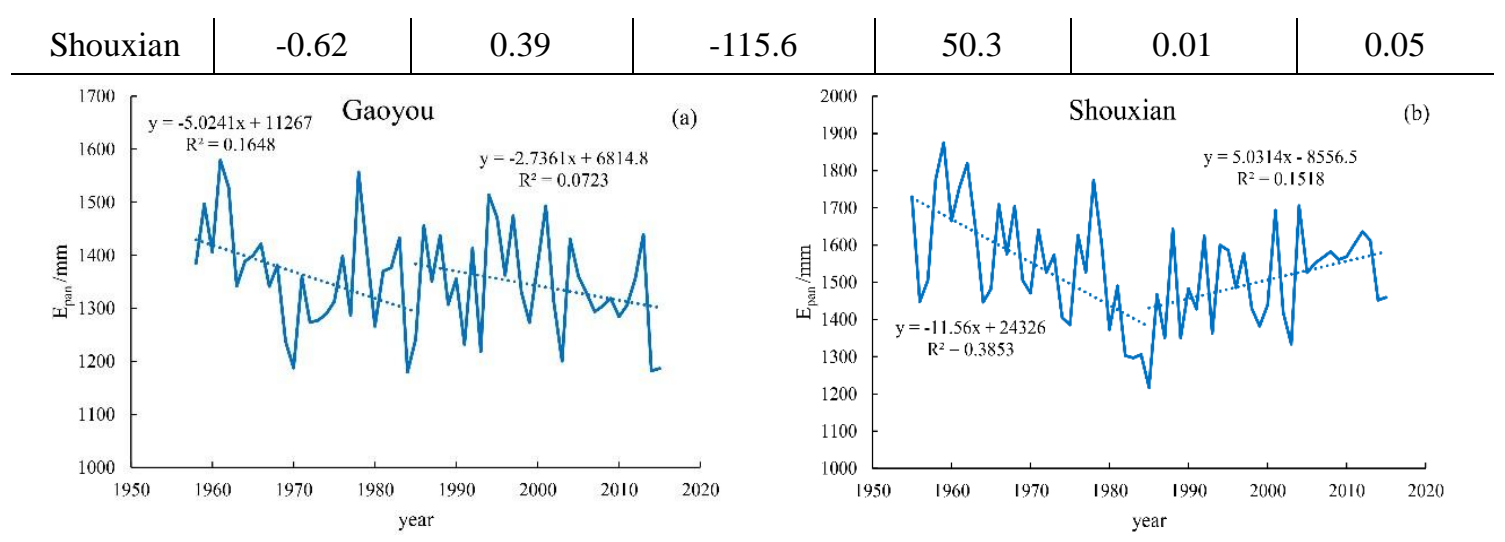

Figure 10. Variations of the average annual $E_{p a n}$ of the second category

For the whole basin, the continuous decreasing tendencies of $\mathrm{E}_{\mathrm{pan}}$ in 26 sites in the HRB all stop in the middle of the 1980s, and the infection points divide the trends after 1985 into three categories, including 12 stations showing non-significant upward trends, 8 stations showing non-significant downward trends and 6 stations showing statistically significant upward trends. Because the sites showing upward trends are more than those presenting downward trends and the upward inclinations are greater than downward inclinations, the $\mathrm{E}_{\mathrm{pan}}$ of the whole basin shows a non-significant upward trend.

\section{Discussion}

In the present study, we used the conversion functions to transfer $\mathrm{E}_{\mathrm{pan}}$ observed by E601 pans into unified D20 data, and the $E_{\text {pan }}$ of the HRB was analyzed. The annual scale adopted in this paper resulted in good simulation effects with the results consistent with the relationship between different evaporation pans (Fu et al., 2014), and the previous researches (Fu et al., 2014; Xu and Singh, 1998; Li et al., 2016) based on the monthly scale presented relatively small errors as well. Therefore, further studies are required to solve the issue of effects of different time scales on the simulation results.

We found that the $\mathrm{E}_{\mathrm{pan}}$ of the $\mathrm{HRB}$ had three variation periods which is different from the nationwide findings (Cong et al., 2008, 2009; Li et al., 2013b; Liu et al., 2011). From 1951 to 1966 , the $\mathrm{E}_{\mathrm{pan}}$ increased at the rate of $257.3 \mathrm{~mm} / 10 \mathrm{a}$, and decreased at the rate of $-195.2 \mathrm{~mm} / 10 \mathrm{a}$ from 1967 to 1985 , and the insignificant rate was $12.8 \mathrm{~mm} / 10 \mathrm{a}$ during 1986 and 2015. The second mutation point of 1985 is consistent with the only mutation point considered in previous papers (Cong et al., 2009; Li et al., 2013b; Liu et al., 2011). Previous researches (Rong et al., 2011; Guo and Ren, 2005; Ren and Guo, 2006) on the existence of evaporation paradox in the HRB may result from the lengths of the selected $E_{p a n}$ series (mostly ended in 2000). On the one hand, the short series could lead to the misunderstanding of the variations of $E_{\text {pan. }}$ On the other hand, those conclusions may also have close relationships with the analytical methods because the commonly used linear regression approach is only suitable for the trend analysis and is difficult to reflect the true changing characteristics.

The results of this paper may have an impact on the early analysis of attribution to the variation of $\mathrm{E}_{\mathrm{pan}}$ of the $\mathrm{HRB}$. In addition, the inconsistent rules of different sites may be 
related to the unique climate and geographical location of the HRB which deserves to be further studied.

\section{Conclusion}

Based on the $\mathrm{E}_{\mathrm{pan}}$ data series from 1951 to 2015, the temporal and spatial variation characteristics of $\mathrm{E}_{\mathrm{pan}}$ of the HRB were analyzed. The main conclusions are listed below.

(1) The average annual $E_{\mathrm{pan}}$ of the HRB was $1565 \mathrm{~mm}$ and the curve of the whole year exhibited a single peak characteristic which meant the seasonal changes were obvious. The average monthly $\mathrm{E}_{\mathrm{pan}}$ mainly peaked in spring and summer, accounting for about $68.4 \%$ of the annual value and was not completely synchronized with the change of $\mathrm{T}_{\mathrm{a}}$. As for the spatial scale, the $\mathrm{E}_{\mathrm{pan}}$ had an obvious zonation characteristic and increased gradually from southeast to northwest, from the coastal area to inland, and from humid basin to semi-humid area.

(2) The average annual $E_{p a n}$ of the HRB changed drastically in 1966 and 1985. The infection points divided the $\mathrm{E}_{\mathrm{pan}}$ series into three periods: the significant increasing period, the significant decreasing period and the non-significant increasing period. Therefore, there existed pan evaporation paradox in the HRB from 1966 to 1985 and then the $\mathrm{E}_{\text {pan }}$ stopped declining and was reversed to weak upward trend again after 1985. The variations of $\mathrm{E}_{\mathrm{pan}}$ in four seasons are similar to the year, and the $\mathrm{E}_{\mathrm{pan}}$ in spring and summer contributes the most to the strong increasing and decreasing period, respectively.

(3) During 1951-1966, $\mathrm{T}_{\mathrm{a}}$ in the HRB increased significantly, and was significantly and positively correlated with $E_{\text {pan. }}$. During 1967-1985, $E_{\text {pan }}$ decreased with the increase of $\mathrm{T}_{\mathrm{a}}$. After 1985, $\mathrm{E}_{\mathrm{pan}}$ was reversed to a non-significant increasing trend with the gradually warming trend. It was showed that the $\mathrm{T}_{\mathrm{a}}$ and $\mathrm{E}_{\mathrm{pan}}$ had contradictory temporal dynamics before and after 1985. As a result, it was difficult to explain the complex mechanism of $E_{p a n}$ by a single factor and the $T_{a}$ was not the important climatic factor affecting $\mathrm{E}_{\mathrm{pan}}$.

(4) Changes of $E_{p a n}$ in sites over the HRB were not entirely consistent with each other. The $\mathrm{E}_{\mathrm{pan}}$ of most of the sites were similar to the basin average, having three obvious changing periods of which the first two were consistent with the average and the other was categorized into two types: the decreasing-to-increasing period and the steep decreasing period. There were only two sites having two obvious changing periods divided by the year 1985 .

Acknowledgements. This study was supported by the National Key R\&D Program of China (Grant No. 2017YFC0405606), the National Natural Science Foundation of China (Grant No. 51579068), and the China Postdoctoral Science Foundation (Grant No. 2017M621612).

\section{REFERENCES}

[1] Brutsaert, W., Parlange, M. B. (1998): Hydrologic cycle explains the evaporation Paradox. - Nature 396: 30.

[2] Chattopadhyay, N., Hulme, M. (1997): Evaporation and potential evapotranspiration in India under conditions of recent and future climate change. - Agricultural \& Forest Meteorology 87: 55-73. DOI: S0168-1923(97)00006-3. 
[3] Cohen, S. Ianetz, A., Stanhill, G. (2002): Evaporative climate changes at Bet Dagan, Israel, 1964-1998. - Agricultural \& Forest Meteorology 111(2): 83-91. DOI: 10.1016/S0168-1923(02)00016-3.

[4] Cong, Z. T., Ni, G. H., Yang, D. W., Lei, Z. D. (2008): Evaporation paradox in China. Advances in Water Science 19(2): 147-152 (in Chinese).

[5] Cong, Z. T., Yang, D. W., Ni, G. H. (2009): Does evaporation paradox exist in China. Hydrology \& Earth System Sciences 13(4): 357-366. DOI: 10.5194/hess-13-357-2009.

[6] Fu, G., Liu, C. M, Chen, S. L, Hong, J. L. (2014): Investigating the conversion coefficients for free water surface evaporation of different evaporation pans. - Hydrological Processes 18(12): 2247-2262.

[7] Golubev, V. S., Lawrimore, J. H., Groisman, P. Y., Speranskaya, N. A., Zhuravin, S. A., Menne, M. J., Peterson, T. C., Malone, R. W. (2001): Evaporation changes over the contiguous United States and the former USSR: A reassessment. - Geophysical Research Letters 28(13): 2665-2668. DOI: 0094-8276/01/2000GL012851.

[8] Güldal, V., Tongal, H. (2008): Cluster analysis in search of wind impacts on evaporation. - Applied Ecology \& Environmental Research 6(4): 69-76. DOI: 10.15666/aeer/0604_069076.

[9] Guo, J., Ren, G. Y. (2005): Recent change of pan evaporation and possible climate factors over the Huang-Huai-Hai watershed, China. - Advances in Water Science 16(5): 666-672 (in Chinese).

[10] He, H. P., Wu, S. J., Ma, M. H., Wen, Z. F., Lv, M. Q., Chen, J. L. (2017): Spatial distribution and temporal trend of pan evaporation in the three gorges reservoir area and its surroundings during 1952-2013. - Applied Ecology \& Environmental Research 15(3): 1594-1610. DOI: 10.15666/aeer/1503_15941610.

[11] Hobbins, M. T., Ramírez, J. A., Brown, T. C. (2001): The complementary relationship in estimation of regional evapotranspiration: an enhanced advection-aridity model. - Water Resources Research 37(5): 1389-1403. DOI: 10.1029/2000WR900359.

[12] Hoffman, M. T., Cramer, M. D., Gillson, L., et al. (2011): Pan evaporation and wind run decline in the Cape Floristic Region of South Africa (1974-2005): implications for vegetation responses to climate change. - Climatic Change 109: 437-452. DOI: 10.1007/ s10584-011-0030-z.

[13] Jaswal, A. K., Rao, P. G. S., De, U. S. (2008): Spatial and temporal characteristics of evaporation trends over India during 1971-2000. - Mausam 59(2): 149-158.

[14] Jhajharia, D., Shrivastava, S. K., Sarkar, D., Sarkar, S. (2009): Temporal characteristics of pan evaporation trends under the humid conditions of northeast India. - Agricultural \& Forest Meteorology 149(5): 763-770. DOI: 10.1016/j.agrformet.2008.10.024.

[15] Jhajharia, D., Dinpashoh, Y., Kahya, E., Singh, V. P., Fakheri-Fard, A. (2012): Trends in reference evapotranspiration in the humid region of northeast India. - Hydrological Processes 26(3): 421-435. DOI: 10.1002/hyp.8140.

[16] Lawrimore, J. H., Peterson, T. C. (2000): Pan evaporation trends in dry and humid regions of the United States. - Journal of Hydrometeorology 1(6): 543-546. DOI: 10.1175/15257541.

[17] Li, Y. Z., Liu, C. M., Liang, K. (2016): Spatial patterns and influence factors of conversion coefficients between two typical pan evaporimeters in China. - Water 8: 422.

[18] Li, Z. L., Li, Z. J., Xu, Z. X., Zhou, X. (2013a): Temporal variations of reference evapotranspiration in Heihe River basin of China. - Hydrology Research 44(5): 904-916. DOI: 10.2166/nh.2012.125.

[19] Li, Z., Chen, Y. N., Shen, Y. J., Liu, Y. B., Zhang, S. H. (2013b): Analysis of changing pan evaporation in the arid region of Northwest China. - Water Resources Research 49(4): 2205-2212. DOI: 10.1002/wrcr.20202. 
[20] Liu, B. H., Xu, M., Henderson, M., Gong, W. G. (2004): A spatial analysis of pan evaporation trends in China, 1955-2000. - Journal of Geophysical Research 109: 12551263. DOI: 10.1029/2004JD004511.

[21] Liu, X. M., Luo, Y. Z., Zhang, D., Zhang, M. H., Liu, C. M. (2011): Recent changes in panevaporation dynamics in China. - Geophysical Research Letters 38: 142-154. DOI: 10.1029/2011GL047929.

[22] Morton, F. I. (1983): Operational estimates of areal evapotranspiration and their significance to the science and practice of hydrology. - Journal of Hydrology 66(1): 1-76. DOI: 10.1016/0022-1694(83)90177-4.

[23] Padmakumari, B., Jaswal, A. K., Goswami, B. N. (2013): Decrease in evaporation over the Indian monsoon region: implication on regional hydrological cycle. - Climatic Change 121(4): 787-799. DOI: 10.1007/s10584-013-0957-3.

[24] Peterson, T. C., Golubev, V. S., Groisman, P. Y. (1995): Evaporation losing its strength. Nature 377: 687-688. DOI: 10.1038/377687b0.

[25] Rayner, D. P. (2007): Wind run changes: the dominant factor affecting pan evaporation trends in Australia. - Journal of Climate 20(14): 3379-3394. DOI: 10.1175/JCLI4181.1.

[26] Ren, G. Y., Guo, J. (2006): Change in pan evaporation and the influential factors over China: 1956-2000. - Journal of Natural Resources 21(01): 31-44 (in Chinese).

[27] Roderick, M. L., Farquhar, G. D. (2002): The cause of decreased pan evaporation over the past 50 years. - Science 298: 1410-1411. DOI: 10.1126/science.1075390-a.

[28] Roderick, M. L., Farquhar, G. D. (2004): Changes in Australian pan evaporation from 1970 to 2002. - International Journal of Climatology 24(9): 1077-1090. DOI: 10.1002/joc.1061.

[29] Roderick, M. L., Farquhar, G. D. (2005): Changes in New Zealand pan evaporation since the 1970s. International - Journal of Climatology 25(15): 2031-2039. DOI: 10.1002/joc. 1262.

[30] Roderick, M. L., Rotstayn, L. D., Farquhar, G. D., Hobbins, M. T. (2007): On the attribution of changing pan evaporation. - Geophysical Research Letters 34: 251-270. DOI: 10.1029/2007GL031166.

[31] Rong, Y. S., Zhou, Y., Wang, W. (2011): Analysis of pan evaporation changes in the Huaihe River basin. - Advances in Water Science 22(01): 15-22 (in Chinese).

[32] Rudd, A., Kay, A. L. (2016): Use of very high resolution climate model data for hydrological modelling: estimation of potential evaporation. - Hydrology Research 47(3): 660. DOI: 10.2166/nh.2015.028.

[33] Ruosteenoja, K., Markkanen, T., Venäläinen, A., Räisänen, P., Peltola, H. (2017): Seasonal soil moisture and drought occurrence in Europe in CMIP5 projections for the 21 st century. - Climate Dynamics D12: 1-16.

[34] Stanhill, G., Cohen, S. (2001): Global dimming: a review of the evidence for a widespread and significant reduction in global radiation with discussion of its probable causes and possible agricultural consequences. - Agricultural \& Forest Meteorology 107(4): 255-278. DOI: 10.1016/S0168-1923(00)00241-0.

[35] Stanhill, G., Möller, M. (2008): Evaporative climate change in the British Isles. International Journal of Climatology 28(9): 1127-1137. DOI: 10.1002/joc.1619.

[36] Tebakari, T., Yoshitani, J., Suvanpimol, C. (2005): Time-space trend analysis in pan evaporation over Kingdom of Thailand. - Journal of Hydrologic Engineering 10(3): 205215. DOI: 10.1061/(ASCE)1084-0699(2005)10: 3(205).

[37] Xu, C. Y., Singh, V. P. (1998): Dependence of evaporation on meteorological variables at different time-scales and intercomparison of estimation methods. - Hydrological Processes 12: 429-442.

[38] Xu, C. Y., Gong, L., Jiang, T., Chen, D. L., Singh, V. P. (2006): Analysis of spatial distribution and temporal trend of reference evapotranspiration and pan evaporation in 
Changjiang (Yangtze River) catchment. - Journal of Hydrology 327: 81-93. DOI: 10.1016/j.jhydrol.2005.11.029.

[39] Xu, J. Q., Haginoya, S., Saito, K., Motoya, K. (2005): Surface heat balance and pan evaporation trends in Eastern Asia in the period 1971-2000. - Hydrological Processes 19(11): 2161-2186. DOI: 10.1002/hyp.5668.

[40] Yang, D. W., Sun, F. B., Liu, Z. Y., Cong, Z. T., Lei, Z. D. (2006): Interpreting the complementary relationship in non-humid environments based on the Budyko and Penman hypotheses. - Geophysical Research Letters 33(18): 122-140. DOI: 10.1029/2006GL027657.

[41] Yang, D. W., Sun, F. B., Liu, Z. Y., Cong, Z. T., Ni, G. H., Lei, Z. D. (2007): Analyzing spatial and temporal variability of annual water-energy balance in nonhumid regions of China using the Budyko hypothesis. - Water Resources Research 43(4): 436-451. DOI: 10.1029/2006WR005224.

[42] Yang, X. Q., Yong, B., Ren, L. L., Zhang, Y. Q., Long, D. (2017): Multi-scale validation of GLEAM evapotranspiration products over China via ChinaFLUX ET measurements. International Journal of Remote Sensing 38(20): 5688-5709. DOI: 10.1080/01431161.2017.1346400.

[43] Zheng, H. X., Liu, X. M., Liu, C. M., Dai, X. Q., Zhu, R. R. (2009): Assessing contributions to panevaporation trends in Haihe River Basin, China. - Journal of Geophysical Research 114(D24): 144-153. DOI: 10.1029/2009JD012203.

[44] Zuo, H. C., Chen, B. L., Wang, S. X., Yang, G., Zuo, B., Wu. L. Y., Gao, X. Q. (2016): Observational study on the complementary relationship between pan evaporation and actual evapotranspiration and its variation with pan type. - Agricultural \& Forest Meteorology 222: 1-9. DOI: 10.1016/j.agrformet.2016.03.002. 